\title{
Maternal and foetal outcome in preterm births in a rural tertiary care centre: a retrospective study
}

\author{
Deeksha Rao Mohan, Vasantha Kumar Singri Gowda*
}

Department of Obstetrics and Gynecology, Sri Devaraj URS Medical College, Bengaluru, Karnataka, India

Received: 24 November 2021

Accepted: 27 December 2021

\section{*Correspondence:}

Dr. Vasantha Kumar Singri Gowda,

E-mail: drvasanthkumar17@gmail.com

Copyright: $\odot$ the author(s), publisher and licensee Medip Academy. This is an open-access article distributed under the terms of the Creative Commons Attribution Non-Commercial License, which permits unrestricted non-commercial use, distribution, and reproduction in any medium, provided the original work is properly cited.

\begin{abstract}
Background: Preterm birth (PTB) is one of the main causes of perinatal morbidity and mortality. It can also result in long term health consequences for both mother and the newborn. The objective was to assess maternal and fetal morbidity and mortality in PTBs.

Methods: A retrospective study was done in the Department of Obstetrics and Gynecology in a tertiary care hospital during January 2020 and June 2020. Ninety-three women with records of preterm births were analyzed for maternal and fetal outcomes. coGuide statistical software was used for data analysis.

Results: $48.39 \%$ of the women were between 20 to 24 years of age. The majority (50.54\%) were primigravida. The main causes for PTB among the study participants were medical disorders (39.78\%), PPROM (29.03\%), spontaneous labor without any underlying cause (18.28\%). $51.61 \%$ had a vaginal delivery, $88.17 \%$ had a live birth. The majority of $52(55.91 \%)$ neonates had birth weights between 1.51 to $2.5 \mathrm{~kg}$. Fifty-nine neonates $(63.44 \%)$ needed NICU admission. The reason for NICU admission in majority $25(26.88 \%)$ was respiratory distress.

Conclusions: Timely, diagnosis and treatment of medical disorders among antenatal women can aid in reducing the occurrence of preterm births and their associated morbidity and mortality. Medical disorders and premature preterm rupture of membrane remain the main causes of preterm birth.
\end{abstract}

Keywords: Preterm birth, Maternal outcome, Fetal outcome, Medical disorders, Intensive care

\section{INTRODUCTION}

PTB is the delivery of fetus before 37 completed weeks. ${ }^{1,2}$ PTB is a global epidemic with a worldwide incidence of 15 million per year. ${ }^{3}$ PTB majorly increases the burden of neonatal mortality, which accounts for almost $70 \%$ of neonatal deaths. It has also contributed to all under-5 mortality cases globally. India, with its highest number of PTB's and the highest number of preterm deaths globally, contributes to $25 \%$ of the worldwide preterm-related deaths. ${ }^{4}$ It exhibits close association with prolonged morbidity comprising cerebral palsy (CP), difficulty in breathing, problems in feeding, developmental delay (DD), retinopathy and issues related to hearing and vision. $^{5-9}$ Not only infants but also women who deliver preterm are at higher risks for critical morbidities in the later stage of their life, including cardiovascular disease and stroke. ${ }^{10-12}$

The WHO has given division on preterm birth into three sub-categories based on gestational age. Category I is extremely preterm, which is birthed less than 28 weeks of gestational age, category II is very preterm when birthed 28 to 32 weeks of gestational age and category III is moderate to late preterm when birthed 32 to 37 weeks. ${ }^{13,14}$ The pathology behind preterm birth is not known and its causes are complicated. Previous literature gives a few commonly identified factors: mechanical factors such as uterine over-distention and cervical incompetence; antepartum hemorrhage or abruption; bacterial infection and inflammation and hormonal changes. ${ }^{15,16}$ There is a difference in the causes and occurrence of preterm births 
in developing countries and developed countries. Looking at developing countries, the crucial causes of preterm birth are the occurrence of infectious diseases and the lack of health care facilities with easy accessibility. ${ }^{17}$

Absurdly, it has been observed that developed and rich nations show higher preterm birth rates than poor and developing nations. A former study backs this statement and makes it logical. In developing and rich nations, advanced maternal age is commonly observed in preterm births patients. Multiple pregnancies due to in vitro fertilization techniques, history of preterm births, habits like smoking, stress, low weight of the mother before pregnancy, high rates of cesarean sections, intrauterine infections to mothers, management of complications during pregnancies results in the initiation of PTBs. ${ }^{18,19}$

Results of a study done by Hodek et al illustrated that parents and caregivers of preterm babies suffered from emotional and mental stress and heavy economic burden. ${ }^{20}$ Medical bills and future health care requirement costs impose a tremendous burden on the health insurance system. They strongly mentioned that parents of PTB and low birth weight have out-of-pocket expenditures (OOPE). Once the infants are discharged from the neonatal unit, the parental burden increases even more and continues longer. ${ }^{20}$ A study conducted in Nigeria concluded that the cost of care of the very low birth weight deliveries in Nigeria is expensive constitutes a significant financial burden on the family. ${ }^{21}$

PTB being an absolute paramount public health concern, awareness about preterm birth and its maternal and foetal outcome is not well studied. We found there was a lack of studies evaluating maternal and fetal outcomes in rural areas. Hence, we conducted this study to assess maternal and foetal morbidity and mortality in PTBs.

\section{METHODS}

An observational descriptive retrospective study was done in a rural tertiary care center, $\mathrm{R}$ L Jalappa teaching hospital, which was attached to Sri Devaraj URS medical college, Tamaka, Kolar, Karnataka, between January 2020 and June 2020. Ninety-three women with recorded preterm births (24-36 weeks six days), 18-34 years of age were included in the study. Records with incomplete data and missing data were excluded from the study. Institutional ethical committee clearance was obtained and this being a retrospective study, no consent was obtained.
Detailed data of the mother regarding the period of amenorrhoea, parity, obstetric history was collected. Detailed data of the fetus was also collected for the study period regarding mode of delivery, the neonatal outcome in terms of gender, birth weight and need for NICU admission was noted from medical records. PTB was considered when women delivered between 24-36 weeks six days of gestation. Birth weight was recorded using an electronic infant weighing scale.

The sample size was calculated by considering maternal outcome as vaginal delivery with preterm as $47.4 \%$ as per a study by Kuper et al. ${ }^{22}$ The other parameters considered were $80 \%$ power and $11 \%$ absolute precision. Based on the above data required sample size was 80 subjects and after considering $15 \%$ non-availability of complete data cases 12 cases were added to the final sample size and hence 93 subjects were included in the final study.

\section{Statistical methods}

The maternal and fetal outcomes were studied. As per the data type, statistics were computed using mean and standard deviation (quantitative variables) and frequency with proportions (categorical variables). Data were analyzed by using coGuide software, V.1.03. ${ }^{23}$

\section{RESULTS}

A total of 93 subjects were included in the final analysis. Of the 93 preterm deliveries which occurred during the study period, 45 patients $(48.39 \%)$ belonged to $20-24$ years of age, whereas $30(32.26 \%)$ belonged to $25-29$ years. 47 (50.54\%) patients were primigravida and 46 (49.46\%) patients were multigravida. When the period of gestation was taken into consideration, 75 patients $(80.65 \%)$ belonged to late preterm ( 32 to 36 weeks) gestation and only $16(17.20 \%)$ belonged to the very preterm ( 28 to 31 weeks) category. Though various reasons led to preterm delivery, $37(39.78 \%)$ patients were delivered in view of some medical disorder and about 27 (29.03\%) patients were delivered due to PPROM. Forty-eight patients $(51.61 \%)$ delivered vaginally and 45 patients $(48.39 \%)$ delivered by caesarean section. $82(88.17 \%)$ of the total 93 deliveries was live birth and 11 newborns $(11.83 \%)$ died. $63(67.7 \%)$ patients had singleton pregnancies and 30 $(32.3 \%)$ had multiple pregnancies (Table 1$)$.

Table 1: Summary of baseline parameters in the study population $(n=93)$.

\begin{tabular}{|lll|}
\hline Parameters & Frequency & Percentage \\
\hline Age (in years) & & 6.45 \\
\hline Up to 19 & 6 & 48.39 \\
\hline 20 to 24 & 45 & 32.26 \\
\hline 25 to 30 & 30 & 12.90 \\
\hline 31 to 34 & 12 & Continued. \\
\hline
\end{tabular}




\begin{tabular}{|c|c|c|}
\hline Parameters & Frequency & Percentage \\
\hline \multicolumn{3}{|l|}{ Parity } \\
\hline Primi para & 47 & 50.54 \\
\hline Multi para & 46 & 49.46 \\
\hline \multicolumn{3}{|c|}{ Gestational age (in weeks) } \\
\hline 24 to $27+6$ days & 2 & 2.15 \\
\hline 28 to $31+6$ days & 16 & 17.20 \\
\hline 32 to $36+6$ days & 75 & 80.65 \\
\hline \multicolumn{3}{|l|}{ Cause of delivery } \\
\hline Medical disorder & 37 & 39.78 \\
\hline PPROM & 27 & 29.03 \\
\hline Spontaneous labour & 17 & 18.28 \\
\hline Others & 12 & 12.90 \\
\hline \multicolumn{3}{|l|}{ Route of delivery } \\
\hline Vaginal delivery & 48 & 51.61 \\
\hline LSCS & 45 & 48.39 \\
\hline \multicolumn{3}{|l|}{ Outcome of delivery } \\
\hline Live & 82 & 88.17 \\
\hline Dead & 11 & 11.83 \\
\hline \multicolumn{3}{|c|}{ Number of conceptus } \\
\hline Singleton & 63 & 67.74 \\
\hline Multiple gestation & 30 & 32.26 \\
\hline
\end{tabular}

Table 2: Summary of foetal outcome.

\begin{tabular}{|lll|}
\hline Parameters & Frequency & Percentage \\
\hline Gender of the baby & 56 & 60.22 \\
\hline Male & 37 & 39.78 \\
\hline Female & & \\
\hline Birth weight (in kg) & 9 & 9.68 \\
\hline$<1$ & 16 & 17.20 \\
\hline 1 to 1.50 & 52 & 55.91 \\
\hline 1.51 to 2.50 & 16 & 17.20 \\
\hline$>2.5$ & & \\
\hline Admission to NICU & 59 & 63.44 \\
\hline Yes & 34 & 36.56 \\
\hline No & & \\
\hline Reason for NICU Admission & 25 & 26.88 \\
\hline Respiratory distress & 5 & 5.38 \\
\hline Intraventricular HMRG & 9 & 9.68 \\
\hline Sepsis & 4 & 4.30 \\
\hline Pulm HMRG & 5 & 5.38 \\
\hline LBW care & 11 & 11.83 \\
\hline Obeservation & 34 & 36.56 \\
\hline Not admitted & & \\
\hline Intubation & 9 & 9.68 \\
\hline Yes & 84 & 90.32 \\
\hline No & & \\
\hline
\end{tabular}

Out of 93, $56(60.22 \%)$ delivered were male babies and 37 $(39.78 \%)$ babies were female. The majority of 52 (55.91\%) neonates had birth weights between 1.51 to 2.5 $\mathrm{kg}$ and 16 neonates were between 1 to $1.5 \mathrm{kgs}$ and $>2.5 \mathrm{~kg}$, respectively. Fifty-nine neonates $(63.44 \%)$ needed NICU admission. The reason for NICU admission in majority 25 $(26.88 \%)$ was respiratory distress. Only nine babies $(9.68 \%)$ needed intubation (Table 2). 


\section{DISCUSSION}

This retrospective study aimed to find the maternal and foetal outcomes in preterm birth in a tertiary care hospital. The study results showed that $48.39 \%$ of the women were between 20 to 24 years of age. The majority (50.54\%) were primigravida. The main causes for PTB among the study participants were medical disorders (39.78\%), PPROM $(29.03 \%)$, spontaneous labor without any underlying cause (18.28\%). The majority, $51.61 \%$ had a vaginal delivery and $88.17 \%$ had a live birth.

Similar maternal outcomes of PTB have been reported in other studies. ${ }^{22,24,25}$ As per the study by Soundarajan et al PPROM was the most common cause of oligohydramnios leading to preterm birth. ${ }^{24}$ This was similar to the current study findings, where $29.03 \%$ of the study population had oligohydramnios caused due to PPROM. Another study by Mahmoodi et al also proved the association between PPROM and preterm birth. ${ }^{26}$ Previous literature had shown that the probability of PTB can be 3-10 times higher in pregnant women with oligohydramnios. ${ }^{27}$

Various medical conditions such as gestational diabetes, hypertension and hypothyroidism remained the major cause of PTB. In the current study, medical disorders occurred in $39.78 \%$ of the women. Medical disorders (e.g. gestational diabetes, hypertension) and obesity that tends to last from one pregnancy to the next, might explain many repetitive spontaneous and induced PTB. Hypertension and pre-eclampsia increased the risk of PTB by 7.3 and 3.6 folds, respectively. ${ }^{24}$ Hypertension caused vasospasm in uterine vessels and reduced blood flow which in turn caused intrauterine growth restriction. PTBs and surgical interventions were likely to be more in women with conditions such as placental abruption, pre-eclampsia and intrauterine growth restriction of the fetus caused due to hypertension. ${ }^{28}$ Renzo et al reported the likelihood of PTB to be 2.6 times greater among women with chronic hypertension. ${ }^{29}$

The fetal outcomes in this current study were $55.91 \%$ had a birth weight range of 1.51 to $2.50 \mathrm{~kg}, 63.44 \%$ of the neonates needed NICU admissions and the reason being respiratory distress $(26.88 \%)$, sepsis $(9.68 \%)$ and for observation. Previous literature also supported these findings and the most common fetal outcome was respiratory distress and birth asphyxia. ${ }^{25,28,30,31}$

The retrospective design had the limitation of lack of follow up of both mother and newborn to assess the long term morbidity. Large-scale prospective COHORT studies were recommended in the future to establish a causal association.

\section{CONCLUSION}

In conclusion, various medical disorders such as gestational diabetes such as gestational diabetes, hypertensive disorders of pregenancy and PRROM remain the major causes of PTB. The newborns have low birth weight requiring NICU admission. Hence, early identification and appropriate treatment of the medical conditions can be made to prevent preterm birth.

Funding: No funding sources

Conflict of interest: None declared

Ethical approval: The study was approved by the Institutional Ethics Committee

\section{REFERENCES}

1. Tucker J, McGuire W. Epidemiology of preterm birth. Br Med J. 2004;329(7467):675-8.

2. WHO: Recommended definitions, terminology and format for statistical tables related to the perinatal period and use of a new certificate for cause of perinatal deaths. Acta Obstet Gynecol Scand. 1977;56(3):247-53.

3. Purisch SE, Gyamfi-Bannerman C. Epidemiology of preterm birth. Semin Perinatol. 2017;41(7):387-91.

4. NIBMG. Preterm Birth Program. National institute of biomedical genomics. Available at: https://www.nibmg.ac.in/?q=content/preterm-birthprogram. Accessed on 2 November 2021.

5. Howson CP, Kinney MV, McDougall L, Lawn JE. Born toon soon: preterm birth matters. Reprod Health. 2013;10:1.

6. Tsimis ME, Al-Hamayel NA, Germaine H, Burd I. Prematurity: present and future. Minerva Ginecol. 2015;67(1):35-46.

7. Huddy CLJ, Johnson A, Hope PL. Educational and behavioural problems in babies of 32-35 weeks gestation. Arch Dis Child. 2001;85(1):23-8.

8. Wang ML, Dorer DJ, Fleming MP, Catlin EA. Clinical outcomes of near-term infants. Pediatrics. 2004;114(2):372-6.

9. Malasa DP. International Encyclopedia of Education. Solomon Islands: Elsevier; 2010: 790-8.

10. Kessous R, Shoham-Vardi I, Pariente G, Holcberg G, Sheiner E. An association between preterm delivery and long-term maternal cardiovascular morbidity. Am J Obstet Gynecol. 2013;209(4):368.

11. Robbins CL, Hutchings Y, Dietz PM, Kuklina EV, Callaghan WM. History of preterm birth and subsequent cardiovascular disease: a systematic review. Am J Obstet Gynecol. 2014;210(4):285-97.

12. Rogers LK, Velten M. Maternal inflammation, growth retardation, and preterm birth: insights into adult cardiovascular disease. Life Sci. 2011;89(13-14):41721.

13. Byrne B, Morrison JJ. Preterm birth. Clin Evid. 2003;10:1700-15.

14. Moutquin JM. Classification and heterogeneity of preterm birth. BJOG Int J Obstet Gynaecol. 2003;110(20):30-3.

15. Villar J, Papageorghiou AT, Knight HE, Gravett MG, Iams J, Waller SA, et al. The preterm birth syndrome: A prototype phenotypic classification. Am J Obstet Gynecol. 2012;206(2):119-23. 
16. Wijnans L, deBie S, Dieleman J, Bonhoeffer J, Sturkenboom M. Safety of pandemic H1N1 vaccines in children and adolescents. Vaccine. 2011;29(43):7559-71.

17. Rao CR, deRuiter LEE, Bhat $P$, Kamath V, Kamath A, Bhat V. A case-control study on risk factors for preterm deliveries in a secondary care hospital, Southern India. ISRN Obstet Gynecol. 2014;2014:15.

18. Belizán JM, Hofmeyr J, Buekens P, Salaria N. Preterm birth, an unresolved issue. Reprod Health. 2013;10(1):58.

19. Tellapragada C, Eshwara VK, Bhat P, Acharya S, Kamath A, Bhat S, et al. Risk factors for preterm birth and low birth weight among pregnant Indian women: A hospital-based prospective study. J Prev Med Public Heal. 2016;49(3):165-75.

20. Hodek JM, Schulenburg JM, Mittendorf T. Measuring economic consequences of preterm birthmethodological recommendations for the evaluation of personal burden on children and their caregivers. Health Econ Rev. 2011;1(1):1-10.

21. Tongo OO, Orimadegun AE, Ajayi SO, Akinyinka OO. The economic burden of preterm/very low birth weight care in Nigeria. J Trop Pediatr. 2009;55(4):262-4.

22. Kuper SG, Sievert RA, Steele R, Biggio JR, Tita AT, Harper LM. Maternal and neonatal outcomes in indicated preterm births based on the intended mode of delivery. Obstet Gynecol. 2017;130(5):1143-51.

23. BDSS Corp. Released 2020. coGuide Statistics software, Version 1.0, India: BDSS corp. Available at: https://www.coguide.in. accessed on 2 November 2021.

24. Soundarajan P, Muthuramu P, Veerapandi M, Mariappan R. Retrospective study factors related to preterm birth in Government Raja Mirasudar hospital and obstetric and perinatal outcome. Int $\mathbf{J}$ Reprod Contraception, Obstet Gynecol. 2016;5(9):3006-10.

25. Granese R, Gitto E, D'Angelo G, Falsaperla R, Corsello G, Amadore D, et al. Preterm birth: Sevenyear retrospective study in a single centre population. Ital J Pediatr. 2019;45(1).

26. Mahmoodi Z, Hoseini F, Shahr HSA, Ghodsi Z, Amini L. The association between maternal factors and preterm birth and premature rapture of membranes. J Fam Reprod Heal. 2010;4(3):135-9.

27. Lo CC, Hsu JJ, Hsieh CC, Hsieh TT, Hung TH. Risk factors for spontaneous preterm delivery before 34 weeks of gestation among Taiwanese women. Taiwan J Obstet Gynecol. 2007;46(4):389-94.

28. Bernabé JVD, Soriano T, Albaladejo R, Juarranz M, Calle ME, Martínez D, et al. Risk factors for low birth weight: A review. Eur J Obstet Gynecol Reprod Biol. 2004;116(1):3-15.

29. DiRenzo GC, Giardina I, Rosati A, Clerici G, Torricelli M, Petraglia F. Maternal risk factors for preterm birth: A country-based population analysis. Eur J Obstet Gynecol Reprod Biol. 2011;159(2):3426.

30. DeSutter P, Bontinck J, Schutysers V, Elst J, Gerris J, Dhont M. First-trimester bleeding and pregnancy outcome in singletons after assisted reproduction. Hum Reprod. 2006;21(7):1907-11.

31. Goldenberg RL, Culhane JF, Iams JD, Romero R. Epidemiology and causes of preterm birth. Lancet. 2008;371(9606):75-84.

Cite this article as: Deeksha RM, Kumar SV. Maternal and foetal outcome in preterm births in a rural tertiary care centre: a retrospective study. Int J Reprod Contracept Obstet Gynecol 2022;11:50-4. 